\title{
ANÁLISE DA UTILIZAÇÃO DA REDE DE ESGOTO SANITÁRIO PELOS RESIDENTES DO \\ LOTEAMENTO ULISSES GUIMARÃES, NO MUNICÍPIO DE CAÇADOR/SC
}

\author{
Cristiane Wegner ${ }^{1}$ \\ Weligton Lucas Baschera ${ }^{2}$ \\ Luciane Dusi ${ }^{3}$
}

\section{RESUMO}

O presente artigo tem por objetivo demonstrar a situação atual da rede coletora de esgotos situada no Loteamento Ulisses Guimarães, no Município de Caçador, Santa Catarina. Através de revisão bibliográfica e realização de questionários com os moradores do local, os acadêmicos constataram a realidade das ligações prediais à rede e da utilização do sistema de tratamento de esgoto pelos residentes do Loteamento, além de promoverem a educação ambiental dos moradores entrevistados.

Palavras-Chave: Rede de esgoto. Esgoto sanitário. Cadastro da rede de esgoto.

\section{ABSTRACT}

The present paper has as goal to demonstrate the current situation of the sewer network located at Ulisses Guimarães Allotment, in the county of Caçador, Santa Catarina. Through literature review and the elaboration of a questionnaire made with the help of the site's residents, the students verified the reality of the building connections to the network and the use of the sewage system at the place, besides promoting the environmental education to the residents Interviewed.

Keywords: Sewerage system. Sanitary sewage. Registration in the sewer network.

\footnotetext{
${ }^{1}$ Acadêmica do Curso de Engenharia Civil, ministrado pela Universidade Alto Vale do Rio do Peixe UNIARP (Caçador). Contato: cristianeweg@gmail.com.

${ }^{2}$ Acadêmico do Curso de Engenharia Civil, ministrado pela Universidade Alto Vale do Rio do Peixe UNIARP (Caçador). Contato: weligton26031995@hotmail.com.

${ }^{3}$ Professora orientadora do projeto, vinculada à Universidade Alto Vale do Rio do peixe - UNIARP (Caçador). Contato: dusiluciane@gmail.com.
} 


\section{INTRODUÇÃO}

Na primeira vez em que o esgotamento sanitário foi executado pelo homem, possuía como intuito protegê-lo dos períodos de aumento vazões causadas pela ação da chuva, destinando as águas para fora da cidade, evitando enchentes ou alagamentos das regiões urbanas (UFCG, 2017).

Foi na cidade Nippur, na Babilônia, onde a primeira galeria de esgoto da história foi encontrada. Na região do vale do Indo, ruas foram criadas com canais de esgotos feitos com tijolos que também recebiam águas provenientes de banheiras e privadas com lançamento de dejetos para os canais (BARROS, 2017).

Escavações foram realizadas em sítios arqueológicos na Índia, onde ruínas com cerca de 3000 a.C demostraram a existência de ruas alinhadas, pavimentadas e com sistema de drenagem subterrâneo, formada por tijolos argamassados, com 50 centímetros de profundidade do nível da rua. Também pode-se constatar a presença de banheiros canalizados com manilhas cerâmicas e rejuntadas com gesso (UFCG, 2017).

No Médio Império do antigo Egito, algumas cidades eram arquitetonicamente planejadas, onde dispunham de galerias em pedras mármore para drenagem de águas superficiais. Na cidade de Amarma, antiga cidade capital do Egito, havia grande presença de moradias com banheiros canalizados, tanto casas pertencentes a nobreza, como casas pertencentes a pessoas mais modesta. Cidades famosas como Tróia, Knossos e Creta, continham avançados sistema hidrossanitários, principalmente em palácios reais. Há indícios que os Incas continham também o conhecimento sobre destinação de esgoto e drenagem de áreas encharcadas em suas cidades (UFCG, 2017).

O hábito de enterrar as fezes ou destiná-las a um lugar retirado já era um costume presente na Grécia antiga. No ano de 312 a.C., os Romanos haviam desenvolvido um aqueduto chamado "Aqua Apia", o qual possuía uma extensão de 17 quilômetros, destinado ao abastecimento de água da cidade de Roma. Foi a primeira civilização que acreditou na importância do estudo sobre o esgotamento sanitário, além da necessidade de oferecer à população o acesso a banheiros públicos, chafarizes, termas e etc. (BARROS, 2017).

Caçador possui apenas 4,6\% da sua população atendida por rede coletora 
de esgoto. Estas redes estão localizadas em bairros de baixa renda e escolaridade, sendo necessária a orientação e acompanhamento de uso por parte da Fundação Municipal de Meio Ambiente - FUNDEMA.

Este trabalho foi proposto com o intuito de educação ambiental dos moradores do Loteamento Ulisses Guimarães e promoção de comparação parcial com o projeto realizado em 2011 pela acadêmica Raquel Gomes de Almeida, do curso de Engenharia Ambiental da Universidade Alto Vale do Rio do Peixe - UNIARP, através do Programa de Apoio a Extensão e Cultura - PAEC, visando contribuir para a melhoria do saneamento básico do município e da qualidade de vida da população. Para tanto, foram adotados como objetivos específicos:

- Conhecer a rede coletora de esgoto;

- Conhecer o processo de cadastro de rede empregado pela FUNDEMA;

- Coletar dados através de questionário e orientar os usuários da rede coletora de esgoto, na área delimitada;

- Compilar os dados recolhidos em planilhas e comparar com o trabalho anterior de Raquel Almeida;

- Realizar os relatórios pertinentes às saídas de campo

- Auxiliar no cadastro da rede municipal de coleta de esgoto, por meio de trabalho de extensão.

\section{DESENVOLVIMENTO}

O desenvolvimento deste artigo é composto pelo referencial teórico sobre o tema abordado, além dos materiais e métodos essenciais para aplicação do tema proposto.

\subsection{DEFINIÇÃO DE REDE COLETORA DE ESGOTO}

O sistema de esgoto sanitário é definido como o conjunto de instalações e obras destinadas a propiciar a coleta, afastamento, condicionamento e disposição final do esgoto sanitário, de forma intermitente e sem riscos para saúde (NETTO, 1998).

A rede coletora de esgoto, integrante do sistema completo, é o conjunto 
constituído por ligações prediais, coletores e seus elementos acessórios (NETTO, 1998). A NBR 9649 (ABNT, 1986, p. 1) ratifica a definição, afirmando que rede coletora de esgoto é o "conjunto constituído por ligações prediais, coletores de esgoto, e seus órgãos acessórios". No Brasil, a rede condutora adotada como padrão é a chamada de sistema separador absoluto, desde 1912, onde as canalizações para coleta de esgoto e águas pluviais são distintas. (NUVOLARI, 2011).

\subsection{IMPORTÂNCIA DA REDE COLETORA DENTRO DO SISTEMA DE ESGOTO}

Segundo Mihelic, Hand e Auer (2012), o esgoto bruto, aquele sem qualquer tratamento, é considerado altamente poluente, apesar de sua concentração de contaminantes parecer pequena. Um metro cúbico de esgoto, dentre um milhão de gramas totais, contém 500 gramas de substâncias poluidoras, capazes de produzirem sérios impactos ambientais se descartadas sem serem tratadas.

A destinação final de qualquer efluente urbano é usualmente um corpo de água. Em razão deste lançamento, surge a possibilidade da geração de inconvenientes, como o desprendimento de mau odores e o sabor estranho na água potável. A saúde pública pode ser afetada pela contaminação das águas de abastecimento, dos balneários e todos os elementos envolvidos no meio. Deste fato provém a finalidade do tratamento dos despejos, que é manter os corpos hídricos livres de tais ameaças (IMHOFF; IMHOFF, 2000).

\subsection{TIPOS DE TRAÇADO DE REDE COLETORA}

Para definição do traçado de uma rede coletora de esgoto necessita-se, segundo Netto (1998), de planta topográfica em escala adequada (1:2000, por exemplo) indicando o arruamento, as curvas de nível, cotas de pontos característicos (como cruzamentos de ruas), talvegues, a eventual rede existente, cursos de água ou outros locais para destinação do esgoto coletado. Indicam-se os trechos dos coletores e sentido de escoamento, adequando os mesmos ao traçado das ruas e às declividades naturais do terreno, distribuindo os órgãos acessórios de acordo com a necessidade.

Quanto ao tipo de traçado a ser adotado, Alem Sobrinho e Tsutiya (2000) enumeram como possibilidades a serem adotadas o traçado perpendicular, em 
leque e radial ou distrital, exemplificados na Figura 1.

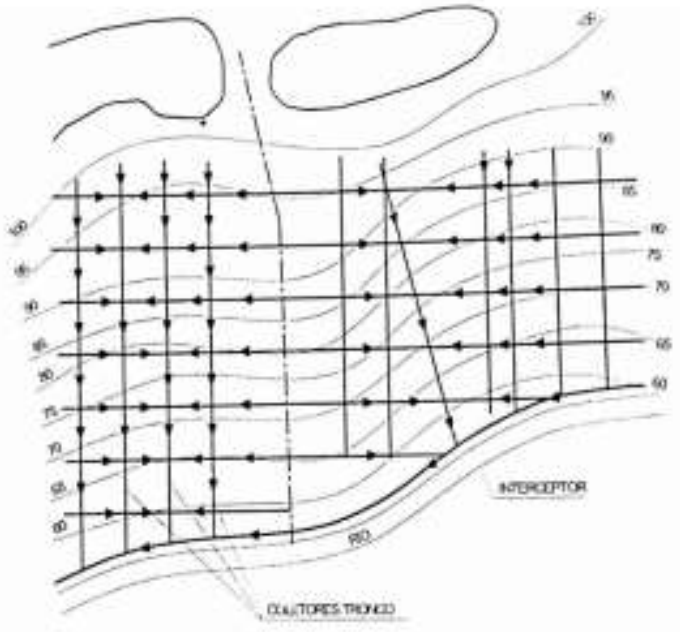

Traçado de rede do tipo perpendieular.

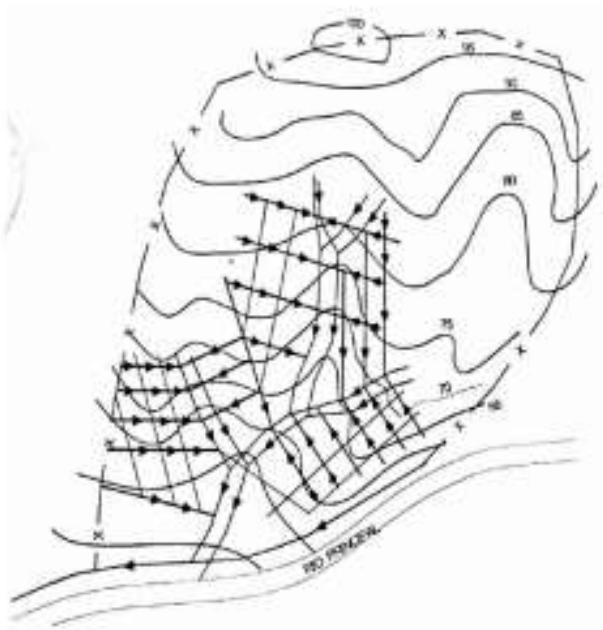

Trasado de rede do tipo em leque.

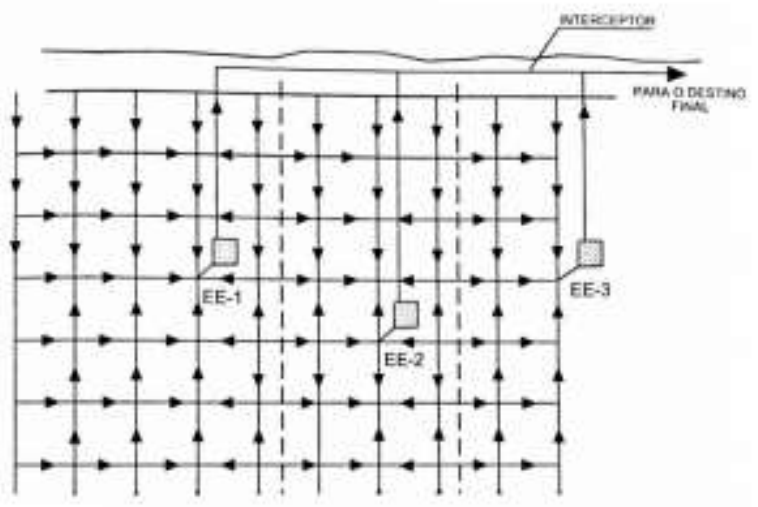

Traçado de efde do tipo radial ou distintat

Figura 1 - Tipos de traçado de rede coletora de esgoto

Fonte: Adaptado de Alem Sobrinho e Tsutiya (2000)

O traçado perpendicular é caracterizado por diversos coletores-tronco independentes, com traçado aproximadamente perpendicular ao curso d'água. Há um interceptor marginal que recepciona estes coletores, levando os efluentes ao destino adequado. $O$ traçado em leque é próprio aos terrenos acidentados, como o encontrado na cidade de São Paulo. Nesse caso, os coletores-tronco correm por fundos de vales ou pela parte baixa das bacias, e neles incidem coletores secundários, com traçado que lembra uma espinha de peixe ou leque. Por fim, o 
traçado radial ou distrital é característico de cidades planas. A cidade é dividida em setores independentes, e em cada um deles são criados pontos baixos, onde os esgotos são dirigidos. Destes pontos, ocorrem recalques até o destino final, como ocorre na cidade do Rio de Janeiro.

Os traçados são influenciados pela disposição dos órgãos acessórios; pela topografia existente no terreno; pelas vias públicas e demais edificações; em função do aproveitamento de canalizações existentes, quando houver; por interferências específicas, como localização de cursos de água; além das exigências contidas em planos diretores (ALEM SOBRINHO; TSUTIYA, 2000).

\subsection{MATERIAIS EMPREGADOS NA REDE COLETORA}

Os principais fatores que devem ser observados para a escolha do material a ser utilizado nas tubulações de esgoto são: características do esgoto; resistência à abrasão e ao ataque químico; resistência a cargas externas; facilidade de transporte; disponibilidade de diâmetros necessários; custo do material; custo de assentamento; custo de transporte; métodos aplicados na construção; e condições locais (BEVILACQUA, 2006).

Os tubos de aço são recomendados nos casos onde ocorrem esforços elevados sobre a linha, como em travessias diretas de grandes vãos, cruzamentos subaquáticos ou ainda quando se deseja uma tubulação com pequeno peso, de absoluta estanqueidade e com grande resistência a pressões de ruptura. Os tubos de PVC são altamente resistentes à corrosão e são bastante utilizados em redes coletoras. Em regiões com lençol freático acima dos coletores de esgoto constitui como principal alternativa de utilização. As suas vantagens de utilização estão na maior velocidade na obra, aproveitamento de mão de obra local, tubos mais longo, lisos, leves, flexíveis e completamente estanques, dentre outras. Os tubos de polietileno de alta densidade são largamente utilizados em ligações prediais de água. Em sistema de esgoto são utilizados em coletores e emissários submarinos. Os tidos de concreto no sistema de esgotos sanitários são normalmente utilizados em emissários, interceptores e coletores tronco, com diâmetros maiores que 400 mm e funcionamento como conduto livre. Os tubos de ferro fundido são utilizados principalmente em linhas de recalque e emissários de recalque, em travessias aéreas, passagens sob rios ou em situações que há necessidade de suportar grandes 
cargas. Os tubos cerâmicos foram utilizados na antiga cidade da Babilônia 250 anos a.C., ultimamente a vitrificarão destes tubos tem sido dispensada, mas há necessidade de acompanhar o comportamento destes (BEVILACQUA, 2006).

Feitos a partir de dois ou mais materiais de classes diferentes (por exemplo, metal/cerâmica, fibras/polímero), compósitos são muito utilizados em diversos setores industriais, como Petroquímico e Aeronáutico, por serem materiais de qualidade superior e possuírem novas propriedades que não podem ser atendidas por outros materiais separadamente, sendo uma classe de materiais bastante ampla e abrangente. Estes materiais se dividem, em geral, em duas ou mais fases que se complementam e fornecem elevadas rigidez e resistência mecânica específicas, resistência à corrosão na presença de maresia, poluentes e uma serie de ácidos e bases fracas, bem como flexibilidade no processo de moldagem. As aplicações de tubulações feitas a partir de materiais compósitos já não são mais novidade e, portanto, foram superados vários obstáculos que incidiram desde sua utilização experimental até as aplicações normatizadas que possuem hoje. (MESQUITA, 2008).

\subsection{PRINCIPAIS ELEMENTOS DA REDE COLETORA}

O fundamento básico do saneamento de uma população é a coleta e o transporte das águas residuais do início até o fim da sua trajetória. A rede coletora trata-se de um conjunto de coletores que possuem condutos que recolhem e transportam as vazões, destinando o despejo. Enquanto os esgotos sanitários são compostos pela rede coletora, os emissários e as unidades de tratamento. Porém há uma determinada etimologia para designar cada elemento dos sistemas de esgoto sanitários (CENTRO SUPERIOR DO ENSINO DO AMAPA - CEAP, 2017).

A Tabela 1 apresenta os itens que, para CEAP (2017), constituem os principais elementos da rede: 
Tabela 1 - Componentes de um Sistema de Esgotos Sanitários

\begin{tabular}{ll}
\hline Elemento & Designação \\
\hline Caixa de Passagem & $\begin{array}{l}\text { Câmara subterrânea sem acesso, localizada em pontos singulares } \\
\text { por necessidade construtiva e econômica do projeto. }\end{array}$ \\
\hline Coletor de Esgoto & $\begin{array}{l}\text { Tubulação subterrânea da rede coletora que recebe contribuição } \\
\text { de esgotos em qualquer ponto ao longo de seu comprimento, } \\
\text { também chamado coletor público. }\end{array}$
\end{tabular}

Coletor Principal

Coletor de esgotos de maior extensão dentro de uma mesma bacia.

Coletor Tronco Tubulação do sistema coletor que recebe apenas as contribuições de outros coletores.

Corpo Receptor Curso ou massa de água onde é lançado o efluente final do sistema de esgotos.

Estação Elevatória de Esgotos

Conjunto de equipamentos, em geral dentro de uma edificação subterrânea, destinado a promover o recalque das vazões dos esgotos coletados a

montante.

Estação de Tratamento de Esgotos

Poço de Visita

Rede Coletora
Unidade do sistema destinada a propiciar ao esgoto recolhido de ser devolvido a natureza sem prejuízos.

Câmara visitável destinada a permitir a inspeção e trabalhos de manutenção preventiva ou corretiva nas canalizações.

Conjunto de condutos e órgãos acessórios destinado a coleta e remoção dos despejos gerados nas edificações, através dos coletores ou ramais prediais.

Dispositivo que permite introdução de equipamentos de limpeza, localizado na extremidade de montante dos coletores.

Terminal de Limpeza

Tubo de Inspeção e Limpeza

Dispositivo não visitável que permite a inspeção externa do trecho e a introdução de equipamentos de limpeza.

Fonte: CEAP (2017)

\subsection{CUSTOS DE INSTALAÇÃO DA REDE}

Além Sobrinho e Tsutiya (2000) expõem que a implantação das redes 
coletoras pode representar até $75 \%$ do custo total de implantação do sistema de coleta e destinação de esgotos sanitários. A Tabela 2 apresenta uma estimativa de custos percentuais de execução das diversas partes da obra de uma rede de esgoto, tendo como base os valores necessários para construção da rede na região Metropolitana de São Paulo. Os autores conseguiram concluir que, por ordem, os fatores que representam maior custo na obra são: escoramento de valas; poços de visita; escavação de valas; reaterro de valas; reposição de pavimentos (asfalto).

Tabela 2 - Estimativa de custos da implantação de redes coletoras

\begin{tabular}{|c|c|c|}
\hline \multirow[t]{3}{*}{ Implantação da obra $(30,8 \%)$} & Canteiro e localização & $0,6 \%$ \\
\hline & Tapumes & $2,1 \%$ \\
\hline & Passadiços & $1,1 \%$ \\
\hline \multirow{4}{*}{$\begin{array}{l}\text { Valas } \\
(61,2 \%)\end{array}$} & Levantamento e pavimento & $1,3 \%$ \\
\hline & Escavação & $10,6 \%$ \\
\hline & Escoramento & $38,8 \%$ \\
\hline & Reaterro & $10,5 \%$ \\
\hline \multirow{5}{*}{$\begin{array}{l}\text { Assentamento de tubulações } \\
(25,1 \%)\end{array}$} & Transporte & $0,4 \%$ \\
\hline & Assentamento & $4,1 \%$ \\
\hline & Poços de visita & $15,5 \%$ \\
\hline & Ligações prediais & $4,6 \%$ \\
\hline & Cadastro & $0,5 \%$ \\
\hline \multirow{3}{*}{$\begin{array}{l}\text { Serviços complementares } \\
(9,9 \%)\end{array}$} & Lastros e bases adicionais & $0,7 \%$ \\
\hline & Reposição de pavimento & $9,2 \%$ \\
\hline & $\begin{array}{l}\text { Reposição de galerias de águas } \\
\text { pluviais }\end{array}$ & $0,1 \%$ \\
\hline
\end{tabular}

Fonte: Adaptado de Alem e Sobrinho (2000) 


\subsection{CONEXÃO DA NSTALAÇÃO PREDIAL NA REDE COLETORA}

Um dos primeiros cuidados é saber se as tubulações do sistema público de esgoto já podem ser usadas no bairro. Somente em áreas em que há rede em operação, em que o esgoto pode ser coletado e tratado, é que a residência pode fazer a conexão do esgoto interno da residência ao sistema coletivo (CASAN, 2017).

Entre as inadequações mais comuns na rede de esgoto estão a ligação da água da chuva, proveniente de calhas e ralos, ao sistema de esgoto. Essa ligação sobrecarrega a rede coletora de esgoto, que não foi dimensionada para absorver esse incremento de vazão, e é uma das principais causas de extravasamentos de esgoto nas cidades, além de prejudicar o bom funcionamento das estações elevatórias e de tratamento de esgoto. Outra inadequação que gera grandes problemas ao funcionamento dos sistemas de esgoto é a falta de caixa de gordura nas residências. Sem esse equipamento a gordura vai direto para as tubulações de esgoto e causa entupimentos (CASAN, 2017).

Para adequada ligação à rede de esgoto deve ser usado tubo PVC para execução do Ramal Interno até o alinhamento predial. Pode-se deixar 10 a $20 \mathrm{~cm}$ para fora do alinhamento. É indicado que a tubulação interna tenha declividade mínima de $2 \%$ ( $2 \mathrm{~cm}$ de profundidade a cada 1 metro na horizontal), para que o esgoto possa escoar para a Caixa de Inspeção. Somente com autorização da operadora do sistema o proprietário poderá desviar a tubulação da fossa/sumidouro para a caixa de inspeção $(\mathrm{Cl})$ que fica instalada na calçada. A partir dessa ligação é recomendável desativar e enterrar fossa e sumidouro, para evitar formação e acúmulo de gases (CASAN, 2017).

\subsection{PRINCIPAIS PROBLEMAS QUE OCORREM NA REDE COLETORA}

Em redes de esgoto do sistema separador absoluto, padronizadas no país, o projeto inicial deve prever a contribuições indevidas, oriundas de infiltrações ocorridas pela penetração da água nas juntas das tubulações, em poços de visita e outras estruturas, além das ocorridas pelas imperfeições dos condutos - e de encaminhamento acidental ou clandestino de águas pluviais. Caso estes valores sejam desconsiderados no cálculo de vazões, podem ocorrer problemas relativos ao subdimensionamento da rede. A influência destas vazões parasitárias pode ser 
observada destacadamente sobre interceptores e emissários, onde a folga de projeto é usualmente menor (NUVOLARI, 2011).

Além disso, sistemas de coleta e transporte de esgoto sanitário, particularmente os localizados em áreas de clima quente e de porte maior, apresentam elevado potencial de formação de produtos geradores de odores ofensivos e corrosão dos condutos de esgotos, quando estes são confeccionados com cimento ou metais (ferro fundido ou aço) (ALEM SOBRINHO; TSUTIYA, 2000).

Neste caso, as substâncias responsáveis pela corrosão do sistema e pelo surgimento de odores desagradáveis encontradas no esgoto sanitário são, geralmente, resultantes da decomposição anaeróbia de matéria orgânica contendo enxofre e nitrogênio, e pela redução de sulfetos e sulfatos. Estes elementos, se altamente concentrados, são tóxicos ao homem e representam riscos aos operadores dos sistemas de esgotos. Para controle da emissão de odores e da corrosão, portanto, é preciso evitar a formação destes elementos, quando possível, ou ao menos amenizá-la. Processos como aeração dos condutos, aplicação de cloro ou peróxido de hidrogênio, adição de nitrato de sódio e limpeza periódica dos trechos de tubulações auxiliam na minimização dos problemas (ALEM SOBRINHO; TSUTIYA, 2000).

\subsection{MANUTENÇÃO DA REDE COLETORA}

Os coletores de esgotos funcionam com escoamento livre, ou seja, se processam em seções parciais de tubulações fechadas e sob pressão atmosférica, apresentando, portanto, uma superfície livre do contato com as paredes da tubulação. O escoamento do esgoto em um conduto é admitido, para efeitos de cálculo, em regime permanente e uniforme. O esgoto sanitário, além de substâncias orgânicas e minerais dissolvidas, leva também substâncias coloidais e sólidos de maior dimensão, em mistura que pode formar depósitos nas paredes e no fundo dos condutos, o que não é conveniente para o seu funcionamento hidráulico, ou seja, para o escoamento (NUCASE, 2008).

No dimensionamento hidráulico das redes coletoras de esgotos deve-se prover condições satisfatórias de escoamento que, simultaneamente, devem atender aos seguintes quesitos (NUCASE, 2008):

- Transportar as vazões máximas e mínimas esperadas. 
- Promover o arraste de sedimentos, garantindo a autolimpeza das tubulações.

- Evitar as condições que favorecem a formação de sulfetos e a formação de

- desprendimento do gás sulfídrico.

A norma NBR 9649 (ABNT, 1986), "Projetos de redes coletoras de esgoto sanitário", regulamenta as condições hidráulicas necessárias nas redes coletoras de esgoto.

Um dos grandes problemas encontrados nas tubulações de esgoto consiste no entupimento das mesmas, devido ao mau uso das pessoas que jogam objetos estranhos nos vasos sanitários e, em alguns casos, diretamente nos poços de visita. Outro grave problema nas redes coletoras de esgotos é a incrustação das tubulações devido à gordura. Na grande maioria dos imóveis mais antigos não existem as caixas de gordura. Muitos usuários fazem o lançamento de gordura de forma indevida que será encaminhada para as redes coletoras. Vazamentos na rede coletora de esgotos podem ocorrer devido à corrosão das tubulações ou por meio de juntas mal executadas. Esse problema é de difícil detecção, pois, normalmente, a água infiltra no solo e, quando se percebe o problema, ele já está em estágio avançado (NUCASE, 2008).

Os principais produtos responsáveis pela produção de odor e corrosão, quando em concentrações elevadas, são, também, tóxicos ao homem e representam um perigo aos operadores de redes coletoras de esgotos. As substâncias responsáveis pela geração de odores ofensivos encontradas em esgoto sanitário são, de modo geral, resultantes da decomposição anaeróbia de matéria orgânica contendo enxofre e nitrogênio e, notadamente, pela redução de sulfatos a sulfetos, também em anaerobiose (NUCASE, 2008).

Uma obra de manutenção de rede de esgotos deve ser objeto de muita atenção, visto que promove problemas no tráfego, ruído de máquinas e equipamentos, sujeira, mau cheiro, risco de acidentes, além da presença de curiosos que circulam nas proximidades. Desta forma há necessidade de planejamento de forma que tenha a duração mais curta possível visando minimizar os impactos causados junto à sociedade e ao meio ambiente (NUCASE, 2008). 


\subsection{MATERIAIS E MÉTODOS}

Este trabalho foi desenvolvido com o intuito de educação ambiental dos moradores do Loteamento Ulisses Guimarães e promoção de comparação parcial com o projeto realizado em 2011 pela acadêmica Raquel Gomes de Almeida, do Engenharia Ambiental da Universidade Alto Vale do Rio do Peixe - UNIARP, através do Programa de Apoio a Extensão e Cultura - PAEC. Na ocasião, Raquel aplicou o mesmo questionário utilizado neste trabalho, em 274 residências, na região abrangida pelo Sistema de Esgotamento Sanitário Ulisses Guimarães.

O projeto atual contou com auxílio da UNIARP e da Fundação Municipal do Meio Ambiente - FUNDEMA, atualmente incorporada à Secretaria Municipal de Agricultura, Meio Ambiente e de Infraestrutura do Município de Caçador, Santa Catarina. Durante a realização das atividades, os acadêmicos Cristiane Wegner e Weligton Lucas Baschera, do Curso de Engenharia Civil, visitaram 83 residências, abrangendo 358 (trezentos e cinquenta e oito) pessoas. Nestes domicílios, aplicaram um questionário contendo perguntas relacionadas às instalações sanitárias (ligações à rede, existência de unidades de tratamento) e distribuíram folders informativos sobre a utilização da rede coletora de esgoto, disponibilizados pela FUNDEMA. Além disso, o período preparatório para realização destas entrevistas foi preenchido com aprofundamento sobre o assunto, para adequada conscientização da população visitada.

A pesquisa foi desenvolvida através de aplicação de questionário, revisão bibliográfica, cômputo das informações obtidas, elaboração de gráficos e discussão dos resultados.

\subsection{RESULTADOS E DISCUSSÃO}

Os dados apresentados foram obtidos pela compilação das informações repassadas pelos moradores do Loteamento Ulisses Guimarães no período de março a junho de 2017.

O Gráfico 1 apresenta a compilação dos dados obtidos por Almeida (2011), quando aplicou o mesmo questionário utilizado neste trabalho, com os dados obtidos através do presente projeto. 


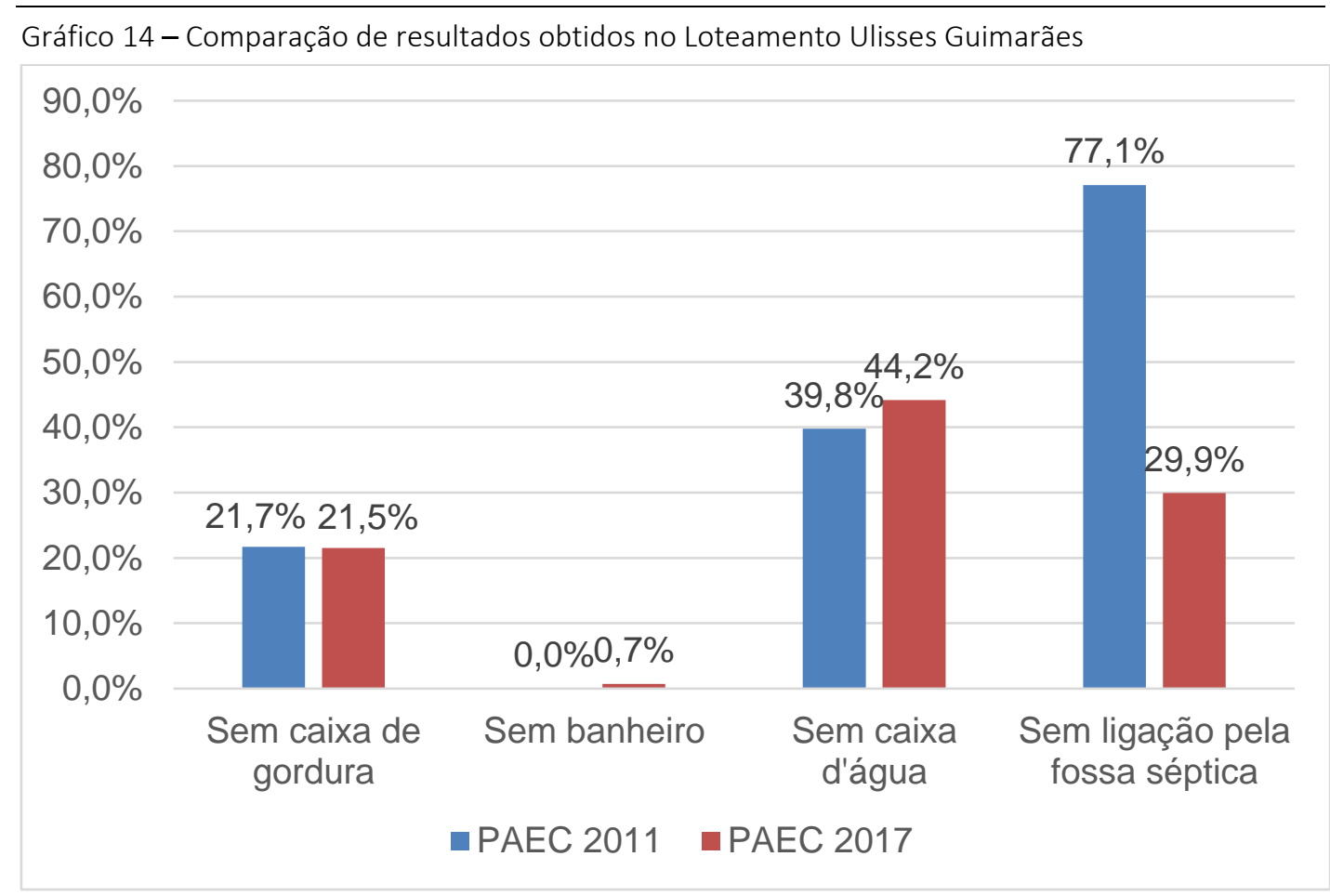

Fonte: Os autores

É possível observar que a quantidade de domicílios que não contam com caixa de gordura após o encanamento da cozinha permanece em aproximadamente $21 \%$ do total. No panorama atual, não foram encontradas residências que não possuíssem banheiro, ao contrário do projeto de 2011. Observou-se melhora no contingente populacional que contava com reservatório de água residencial. Em 2011, 44,2\% dos entrevistados não possuíam caixa d'água, dado que atualmente é de $39,8 \%$.

Além disso, nota-se a melhoria das ligações à rede coletora de esgoto. Em 2011,70\% da população fazia sua ligação à rede através da fossa séptica, dado que passou a ser de aproximadamente $30 \%$. Assim, de acordo com as informações contidas no folder ilustrativo, considera-se que, atualmente, mais residências possuem ligações adequadas à rede.

O Gráfico 2 apresenta a situação constatada nas ligações de esgoto sanitário à rede coletora do Loteamento. Em função dos parâmetros adotados nesta pesquisa para classificação das ligações divergirem com os aplicados por Almeida (2011), não puderam ser realizadas comparações precisas com as informações 
obtidas naquele estudo.

Gráfico 2 - Situação das Ligações de Esgoto Sanitário

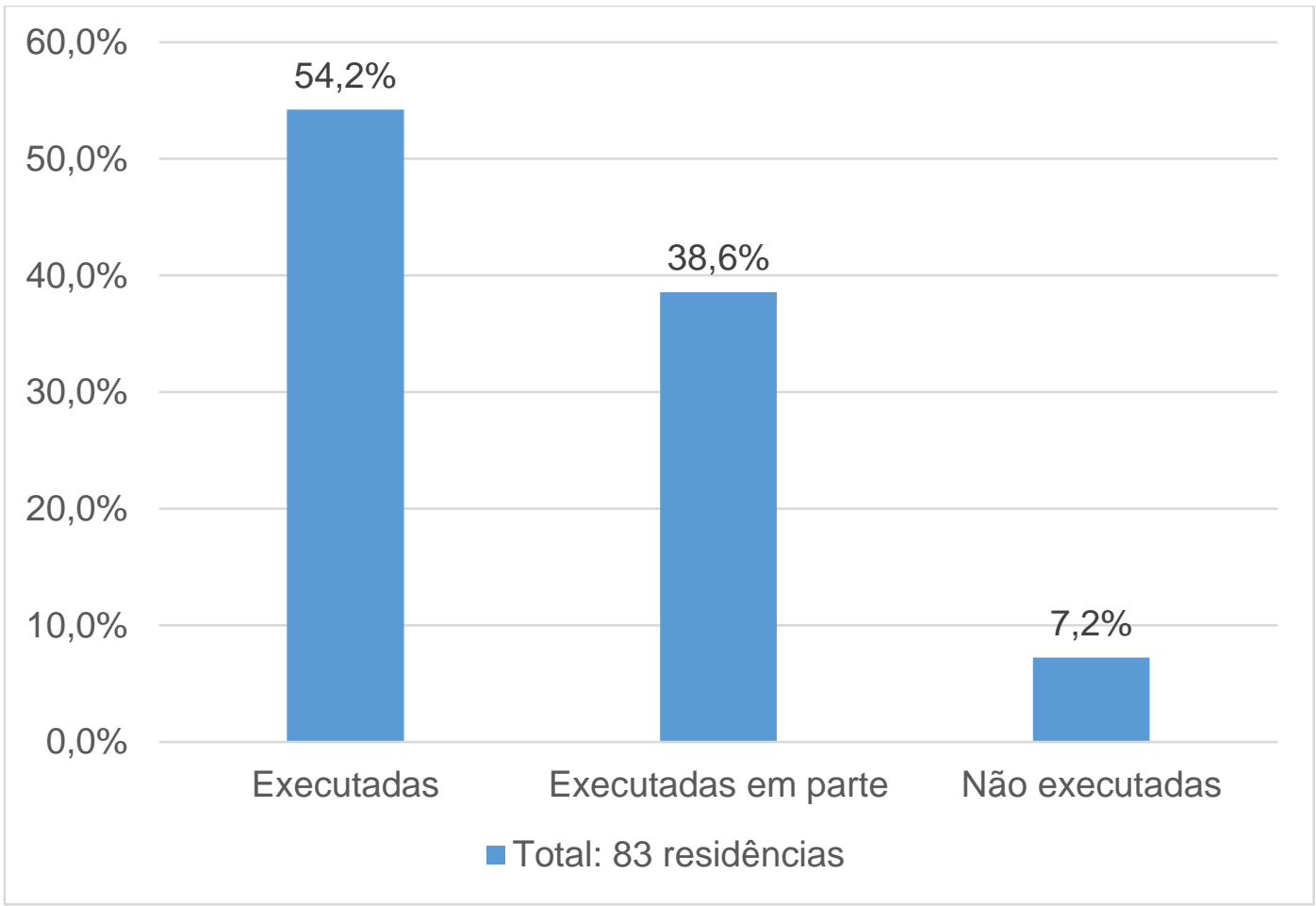

Fonte: Os autores

Neste trabalho, os autores consideram como ligação executada aquela onde ocorre passagem por caixa de gordura, direcionada ao terminal de ligação e posteriormente à rede; ligação executada em parte quando o efluente passar por fossa séptica, além dos elementos da ligação ideal, ou quando não possuir caixa de gordura; e ligação não executada quando a destinação do efluente doméstico não é a rede coletora de esgoto, podendo ser lançado à fossa séptica e filtro anaeróbio.

Através desta constatação, notou-se que 45 residências apresentavam ligação executada, onde havia caixa de gordura e o efluente não passava por fossa séptica.

O Gráfico 3 apresenta as residências com ligação parcialmente executada. 


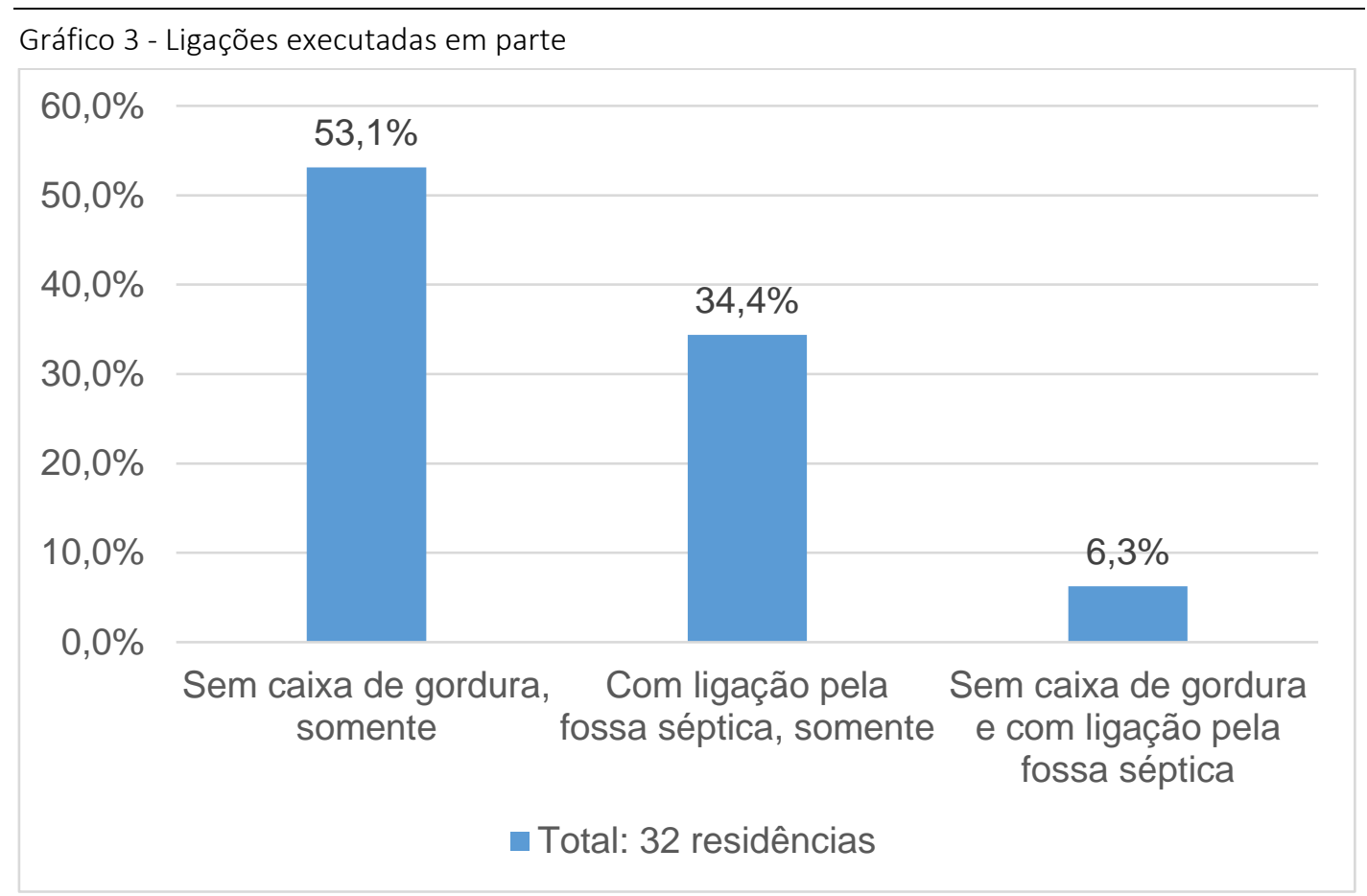

Fonte: Os autores

Observa-se que $53,1 \%$ das residências somente não possuíam caixa de gordura, item necessário à retirada dos elementos graxos do efluente residencial, que são mais difíceis de serem eliminados nos processos que ocorrem na Estação de Tratamento de Esgoto - ETE. Dentre as 32 residências com ligação parcialmente executada, em $33,4 \%$ delas o efluente passava por fossa séptica antes de ser destinado à rede. Por fim, em $6 \%$ dos casos, ocorreram ambas as situações: não havia caixa de gordura e o efluente passava por fossa séptica ativa antes de ser destinado à rede.

O Gráfico 4 apresenta as residências onde o efluente doméstico não é destinado à rede coletora de esgoto sanitário. 


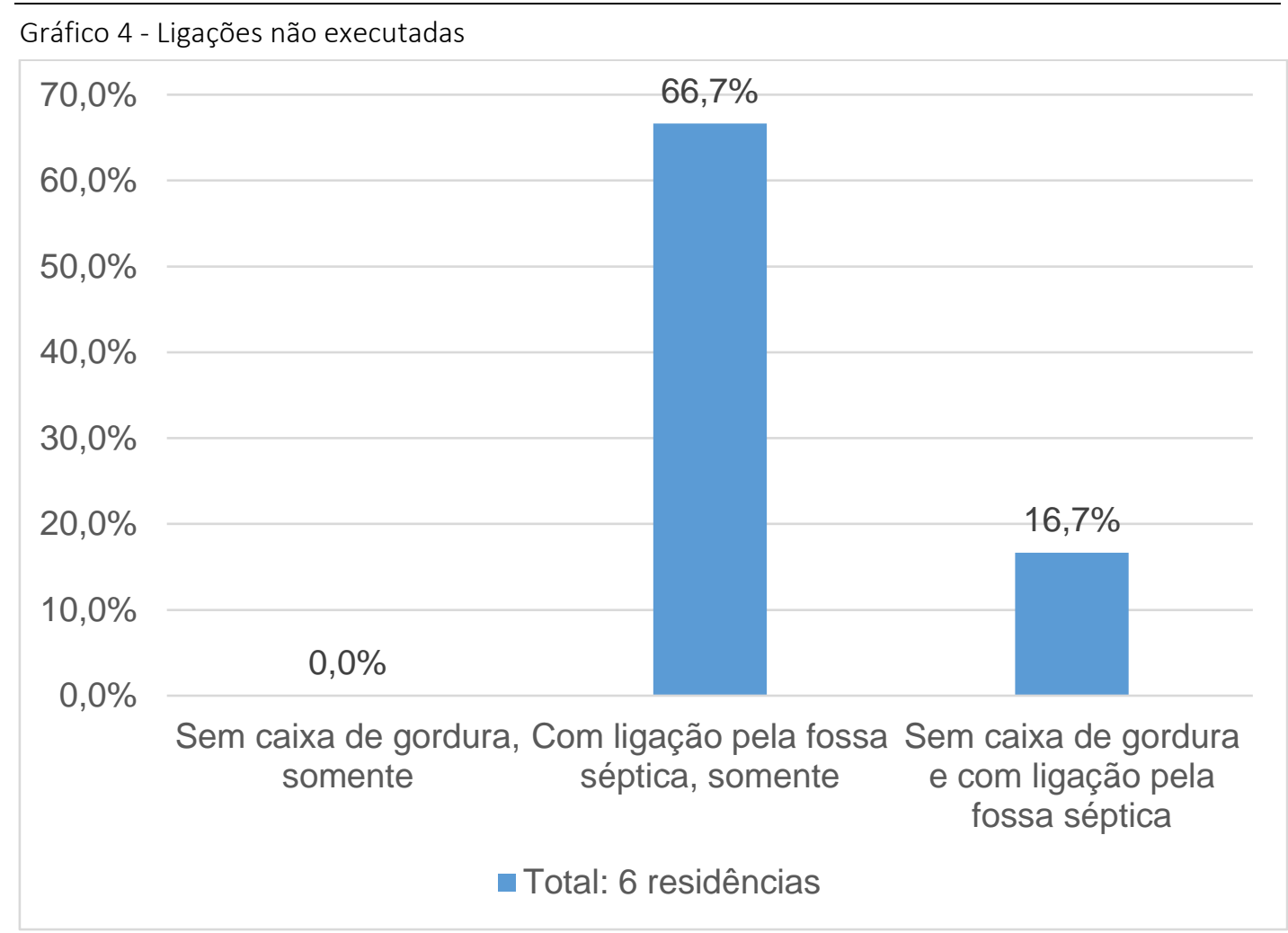

Fonte: Os autores

É notório que $67 \%$ das residências sem ligação à rede destinava seu esgoto à fossa séptica, contando com caixa de gordura. Uma residência, que representa $16,6 \%$ do total, destinava o efluente à fossa séptica, mas sem caixa de gordura. Uma residência possuía caixa de gordura, mas não fossa séptica, e seu esgoto não era destinado à rede coletora. Sendo assim, não possuía forma de destinação final adequada para seu esgoto.

$\mathrm{Na}$ ocasião das entrevistas, foi entregue folder com intuito de educação ambiental, com informações relevantes que puderam ser repassadas aos moradores. Neste período, foram tratados de temas como: a forma adequada de realizar o sistema sanitário residencial; destinação correta do óleo de cozinha usado; o correto escoamento da água oriunda das chuvas nas calhas; a importância de evitar a disposição de resíduos sólidos no encanamento de esgoto; entre outros.

Desta forma, foi possível constatar que os moradores possuem certa consciência de destinação do lixo gerado, da necessidade de disposição do resíduo 
sólido para coleta dos caminhões de lixo - para posterior destinação ao aterro sanitário -, além de deterem conhecimento de que a água pluvial não deve ser ligada à rede de coleta de esgoto.

Parte dos entrevistados não possuía conhecimento das possíveis destinações do óleo de cozinha utilizado - cuja recolhimento é efetuada pelo caminhão de coleta seletiva de resíduos, desde que o óleo esteja acondicionado em litro descartável -, nem do dia em que este caminhão faz a coleta no bairro. Por outro lado, diversos moradores faziam uso deste óleo em outras atividades, como a fabricação de sabão ou incorporação na alimentação de animais domésticos, evitando sua destinação à rede.

Além disso, de acordo com os gráficos, nota-se a inexistência de caixa de gordura em parte das residências visitadas. Segundo a Norma Brasileira - NBR 8160 (ABNT, 1999), é recomendado o uso de caixas de gordura quando os efluentes contiverem resíduos gordurosos, sendo que isto ocorre, nas residências, após canalizações de pias de cozinha ou máquinas de lavar louças.

Assim, os autores sugerem, em relação ao folder, a incorporação de maiores informações referentes à coleta seletiva de resíduos, como o calendário das visitas à região; acréscimo de maiores informações descritivas sobre a destinação do óleo de cozinha usado; e adição de detalhes que exponham a necessidade de caixas de gorduras nas ligações.

Ademais, durante período de reconhecimento do tema, notou-se que não há órgão responsável pela fiscalização das instalações que destinam o esgoto à rede coletora. A Vigilância Sanitária do Município, que realiza este procedimento no restante da cidade - onde predominam sistemas individuais de tratamento de esgoto -, se exime da responsabilidade de fiscalizar o loteamento. A FUNDEMA, responsável pela manutenção da rede no local, também não faz esta fiscalização. Desta forma, sugere-se que estas ligações passem a ter algum tipo de acompanhamento obrigatório durante sua execução, fator que certamente facilitará a operação da rede, evitando diversos problemas lá recorrentes.

Em caso de existir necessidade de atualização das informações obtidas com este projeto, recomenda-se utilização de folder ilustrativo atualizado com as informações anteriormente citadas. Além disso, deve-se analisar quais informações constantes no questionário são realmente relevantes para alcançar os objetivos 
propostos. Para tanto, o trabalho será facilitado se algumas perguntas passarem por reformulação, visando torná-las mais concisas, menos redundantes e abertas a diversas interpretações. Por fim, entende-se que quanto mais residências puderem ser visitadas, mais precisas serão as estimativas obtidas.

\section{CONSIDERAÇÕES FINAIS}

Ao longo das atividades realizadas, observou-se que a população do Loteamento Ulisses Guimarães possui maior conhecimento sobre a importância do saneamento básico, quando comparado ao trabalho de Almeida (2011), assim como sobre a utilização adequada da rede para que o tratamento realizado na Estação de Tratamento de Esgotos - ETE não seja prejudicado. Notou-se a necessidade de elucidação de dois pontos explicitados no folder educativo, para facilitar o entendimento da população do loteamento sobre a maneira correta do descarte do óleo de cozinha e da adequada ligação de calhas de chuvas, que não devem ser destinadas à mesma tubulação coletora do efluente sanitário.

Além disso, percebeu-se a receptividade geral da população visitada. Grande parte dos moradores demonstraram interesse nas informações repassadas sobre saneamento básico e funcionamento geral de uma ETE. Dentre as 85 residências visitadas, somente em duas delas os moradores recusaram-se responder as questões, totalizando uma aprovação de $97,64 \%$.

Analisando as informações coletadas, entende-se que a educação sanitária é um direito destinados a toda uma população, e que a conscientização ambiental sobre o assunto oferece inúmeros benefícios, pois além de facilitar a operação da rede coletora, traz também melhorias para a saúde física e intelectual dos habitantes do Loteamento Ulisses Guimarães.

\section{REFERÊNCIAS}

ALEM SOBRINHO, Pedro; TSUTIYA, Milton Tomoyuki. Coleta e Transporte de Esgoto Sanitário. 2. ed. São Paulo: Departamento de Engenharia Hidráulica e Sanitária da Escola Politécnica da Universidade de São Paulo, 2000.

ALMEIDA, Raquel Gomes de. Educação Sanitária como reflexo do nível perceptível 
da importância de uma ETE para a comunidade do Loteamento Ulisses Guimarães no Município de Caçador/SC. Caçador, Santa Catarina. Programa de Apoio a Extensão e Cultura - PAEC. Dezembro de 2011.

ASSOCIAÇÃO BRASILEIRA DE NORMAS TÉCNICAS - ABNT. NBR 9649: Projeto de redes coletoras de esgoto sanitário. Rio de Janeiro, 1986.

ASSOCIAÇÃO BRASILEIRA DE NORMAS TÉCNICAS - ABNT. NBR 8160: Sistemas prediais de esgoto sanitário - Projeto e execução. Rio de Janeiro, 1999.

BARROS, Rodrigo. A história do Saneamento Básico na Idade Antiga. Disponível em: $<$ http://www.rodoinside.com.br/historia-saneamento-basico-na-idade-antiga/>. Acesso em: 08 jun. 2017.

BEVILACQUA, N. Materiais de tubulações utilizadas em sistemas de coleta e transporte de esgotos sanitários. Estudo de caso da área norte de São Paulo. 2006. 169 p. Dissertação (Mestrado em Engenharia) - Escola Politécnica da Universidade de São Paulo, São Paulo. Disponível em: <https://www.google.com.br/?gws_rd=cr \&ei=25VWWdzelsSiwQSy_Y3IDw\#q=

BEVILACQUA,+N.+Materiais+de+tubula\%C3\%A7\%C3\%B5es+utilizadas+em+sistema s+de+coleta+e+transporte+de+esgotos+sanit\%C3\%A1rios>. Acesso em: 30 jun.

2017.

CASAN - Companhia Catarinense de Águas e Saneamento. Disponível em: <http://www.casan.com.br/noticia/index/url/como-fazer-a-ligacao-de-seu-imovela-rede-de-esgoto\#0>. Acesso em: 09 jul. 2017.

Centro de Ensino Superior do Amapá - CEAP. Componentes de Sistemas de Esgotos Sanitários. Disponível em:

<http://www.ceap.br/material/MAT15052014142755.pdf>. Acesso em: 23 jun. 2017.

IMHOFF, Karl; IMHOFF, Klaus R. Manual de Tratamento de Águas Residuárias. São Paulo: Edgard Blücher LTDA, 2000. 301 p.

MESQUITA, F. N. de A. Simulação do comportamento mecânico de tubos em PRFV submetidos à pressão hidrostática. 2008. 108 p. Dissertação (Mestrado em Engenharia) - Faculdade de Tecnologia da Universidade de Brasília, Brasília. Disponível em: <http://repositorio.unb.br/bitstream/10482/3007/1/2008 _FaustoNogueiraAlmeidaMesquita_orig.pdf>. Acesso em: 30 jun. 2017.

MIHELIC, James R.; HAND, David W.; AUER, Martin T. Tratamento de Águas 
Residuárias. In: MIHELIC, James R.; ZIMMERMAN, Julie Beth. Engenharia Ambiental: Fundamentos, Sustentabilidade e Projeto. Rio de Janeiro: LTC, 2012. Cap. 11, p. 410-461.

NETTO, José Martiniano de Azevedo. et al. Manual de Hidráulica. 8. ed. São Paulo: Edgar Blücher LTDA, 1998. 680 p.

NUCASE. Esgotamento sanitário: operação e manutenção de redes coletoras de esgotos - guia do profissional em treinamento, nível 2 / Ministério das Cidades. Secretaria Nacional de Saneamento Ambiental (org.). - Brasília: Ministério das Cidades, 2008.

NUVOLARI, Ariovaldo (coord.). Esgoto Sanitário: coleta, transporte, tratamento e reuso agrícola. 2. ed. São Paulo: Edgar Blücher LTDA, 2011.

Universidade Federal de Campo Grande - UFCG. Evolução dos Sistemas de Esgotamento. Disponível em:

$<$ http://www.dec.ufcg.edu.br/saneamento/Historia.html>. Acesso em: 08 de junho de 2017. 